\title{
Evaluation of the Direct and Enrichment Iso 10272 Methods for the Detection of Campylobacter Spp. in Chicken Meat
}

\section{-Author(s)}

\section{Benetti TM' \\ Abrahão WM",III \\ Ferro ID ${ }^{\mathrm{IV}}$ \\ Macedo REFIV \\ Oliveira TCRM}

Department of Food Science and Technology, Center for Agricultural Sciences, State University of Londrina, Londrina, PR, Brazil.

" Section of Food Microbiology, Central Laboratory of the State of Paraná, Curitiba, PR, Brazil.

III Department of Pharmacy, Division of Health Sciences, Federal University of Paraná, Curitiba, PR, Brazil.

Iv Master in Animal Science, School of Agricultural Sciences and Veterinary Medicine, Pontifícia Universidade Católica do Parana, São José dos Pinhais, PR, Brazil.

Evaluation of ISO 10272 methods in chicken meat

\section{ABSTRACT}

In 2006, the International Organization for Standardization (ISO) published two standard protocols for the detection and enumeration of Campylobacter spp. in foods: the ISO 10272-2(direct method) and the ISO 10272-1 (enrichment method). The aim of this study was to compare the efficiency of these two methods in the detection of Campylobacter spp. and propose a modification in the enrichment method. Compared with the enrichment method, the direct method yielded a higher number of positive results for Campylobacter spp. and, consequently, presented higher sensitivity percentage. The isolation of Campylobacter spp. was more difficult when $10 \mathrm{~mL}$ of rinse was used in the enrichment method, which is currently recommended by the ISO protocol. Therefore, different rinse volumes were tested ( 2.5 and $5 \mathrm{~mL}$ ). The most efficient recovery of Campylobacter spp. occurred when $2.5 \mathrm{~mL}$ of rinse were used in the enrichment method, most likely due to a lower number of microbial contaminants than that present in the 5 or $10 \mathrm{~mL}$ rinses. The proposed modification of the enrichment method will contribute to the food analysis by improving the detection of Campylobacter spp. in chicken carcass.

\section{INTRODUCTION}

Campylobacter spp. is a common cause of bacterial foodborne illnesses that have been associated with autoimmune diseases, including Guillain-Barre syndrome (GBS), Miller Fisher syndrome, arthritis, and Reiter's syndrome (Oliveira et al., 2005; Snelling et al., 2005). Poultry and poultry products are considered the main vehicle of transmission to humans (Jacobs-Reitsma et al., 2008; Casaril 2010).

The control of Campylobacter jejuni contamination in poultry carcasses has increased with the demand of international trade (Scarcelli et al., 2005; Humphrey et al., 2007). Brazil is the largest exporter and Parana state the largest producer of poultry meat in the country (IBGE 2010). The prevalence of Campylobacter contamination in poultry carcasses in Brazil ranges from 38 to 93.3\% (Maziero \& Oliveira 2010; Franchin et al., 2007; Aquino et al., 2002; Dias et al., 1990).

False-negative results have been obtained during the detection of Campylobacter spp. in poultry meat due to the nutritional and environmental requirements of these bacteria and to their difficulty in outcompeting bacteria present in the product (Edson et al., 2009). Therefore, the use of adequate enrichment broths, selective media, and conditions that allow the consistent growth of Campylobacter spp. are important for their isolation from poultry meat (Habib et al., 2011). In 2006, the International Organization for Standardization (ISO) published the ISO 10272 protocols for the detection and enumeration of Campylobacter spp.in foods destined for human and animal consumption. Part 1 of the protocol (ISO 10272-1) describes the detection of Campylobacter spp. after selective enrichment of poultry 
Benetti TM, Abrahão WM, Ferro ID, Macedo REF, Oliveira TCRM
Evaluation of the Direct and Enrichment Iso 10272 Methods for the Detection of Campylobacter Spp. in Chicken Meat carcass rinse (enrichment method) and Part 2 (ISO 10272-2) describes the detection and colony count of Campylobacter spp. before selective enrichment (direct method).

The aim of this study was to compare the ISO 10272-2 (direct method) and ISO 10272-1 (enrichment method) protocols for the detection of Campylobacter spp. in poultry carcasses. Modification of the enrichment method was suggested for better isolation of Campylobacter spp. in chicken carcass.

\section{MATERIALS AND METHODS}

\section{Sample collection}

A total of 80 samples of refrigerated whole broiler carcass from 12 brands were analysed, 5 to 8 samples per brand. The samples were collected in their original packaging from different retailers of Curitiba, Paraná, and sent to the laboratory under refrigeration. After the removal of the packing and the giblets, the samples were placed in sterile plastic bags and weighed. One $\mathrm{mL}$ of buffered peptone water $(0.1 \%)$ was added per gram of sample, and the surface of the carcass was hand massaged for approximately two minutes. Aliquots of rinse were used for the detection of Campylobacter spp. before (direct method) and after (enrichment method) selective enrichment.

\section{ISO 10272-2 (Direct Method): Detection and Colony Count of Campylobacter spp. before Selective Enrichment}

Aliquots of the rinse $(0.1 \mathrm{~mL})$ prepared as previously described were streaked in duplicate on MCCDA plates (CM 739) (Oxoidlnc., Ogdensburg, N.Y., U.S.A.), which were supplemented with cefoperazone $(16 \mathrm{mg})$ and amphotericin B (5mg) (SR 155E) (Oxoidlnc., Ogdensburg, N.Y., U.S.A.), and on modified Bolton agar (MBA) plates. The plates were incubated at $41.5 \pm 0.5^{\circ} \mathrm{C}$ for $48 \mathrm{~h}$ under microaerobic conditions generated by the injection of a mixture of gases $\left(5 \% \mathrm{O}_{2}, 10 \% \mathrm{CO}_{2}\right.$ and $85 \% \mathrm{~N}_{2}$ ) (Air Liquide, São Paulo, Brazil) into special jars. The MBA plates and the microaerobic system were prepared as described by Franchin et al. (2005).

In each plate, five characteristic colonies were observed under the microscope and evaluated for their characteristic morphology. The colonies with the characteristic morphology were sub-cultured on Trypticase Soy Agar (TSA) plates, which were supplemented with 5\% defibrinated sheep blood (Newprov, Curitiba, Paraná, Brazil), and incubated at $36 \pm 1{ }^{\circ} \mathrm{C}$ for 24 and $48 \mathrm{~h}$ under microaerophilic conditions. Subsequently, oxidase and catalase tests were carried out and, when the results were positive, a biochemical identification test was performed using the API CAM system (Biomerieux S.A., Lyon, France). Campylobacter was molecularly confirmed by realtime $P C R$, and quantified using the equation $Q=n$ $x 2.5$, where $n$ corresponded to the total number of biochemically identified colonies. The results were expressed as CFU/g.

\section{ISO 10272-1 (Enrichment Method): Detection of Campylobacter spp. after Selective Enrichment}

In 80 whole broiler carcass samples, $10-\mathrm{mL}$ aliquots of rinse were transferred to $90 \mathrm{~mL}$ of Bolton broth, which was supplemented with cefoperazone (10mg), vancomyc in (10mg), trimethoprim (10mg), and amphotericin B (5mg)(SR208E)(Oxoid Inc.,Ogdensburg, N.Y., U.S.A.). The enrichment broths were incubated at $37^{\circ} \mathrm{C}$ for $4 \mathrm{~h}$ followed by an additional incubation at $41.5 \pm 0.5^{\circ} \mathrm{C}$ for $48 \mathrm{~h}$ under microaerobic conditions. The enrichment broths were plated onto mCCDA agar and MBA agar plates that were incubated at $41.5 \pm$ $0.5{ }^{\circ} \mathrm{C}$ for $48 \mathrm{~h}$ under microaerobic conditions. The biochemical identification of Campylobacter spp. colonies was performed as described in the ISO 102722 protocol (2006). The Campylobacter genus was molecularly confirmed by real-time PCR.

\section{ISO 10272-1 (Enrichment Method): Evaluation of different volumes of rinse for detection of Campylobacter spp. after Selective Enrichment}

In 18 whole broiler carcass samples, the detection of Campylobacter spp. by the enrichment method was carried out using different volumes of rinse (2.5, 5.0 , and $10.0 \mathrm{~mL}$ ) added to $90 \mathrm{~mL}$ of Bolton broth, as previously described. The selective enrichment, the biochemical identification and the molecular confirmation of Campylobacte nwere performed as described in section 2.3.

\section{Molecular confirmation of Campylobacter spp. by real-time PCR}

The molecular confirmation of the colonies plated onto mCCDA agar and MBA agar plates and biochemically identified as Campylobacter spp. was performed using TaqMan® real-time PCR.Bacterial DNA extraction was performed using the NewGene Prep and NewGene Preampfrom Simbios Technology (Canoas, Rio Grande do Sul, Brazil).The PCR mixture consisted of a final volume of approximately $30 \mu \mathrm{L}: 28 \mu \mathrm{L}$ of TaqMan Master Mix Kit (Simbios Technology) composed of buffer, dNTPs, ultrapure water, primers 
and probe, $0.32 \mu \mathrm{L}$ of Taq polymerase (Simbios Technology), and $2 \mu \mathrm{L}$ of DNA.

The $P C R$ reactions were carried out in a Thermocycler 7500 (Applied Biosystems, Foster City, CA, U.S.A.) with the following conditions: an initial denaturation step at $95^{\circ} \mathrm{C}$ for 3 min, followed by 40 cycles at $95^{\circ} \mathrm{C}$ for 15 $\mathrm{S}$, and a final annealing and elongation step at $60^{\circ} \mathrm{C}$ for $1 \mathrm{~min}$.

Purified DNA from Campylobacter jejuni ATCC 33291 was used as a positive control. Ultrapure water and buffered Master Mix Kit with Taq polymerase were used as negative controls.

\section{Analyses of the results}

The prevalence of Campylobacter spp. in the chicken meat samples was expressed as a percentage. The sensitivity and specificity of the two methods were calculated according to the model described by Hanrahan \& Madupu (1994). The sensitivity and specificity percentages were calculated considering as samples positive for Campylobacter those which culture results were confirmed by real-time PCR. Accuracy and correlation analyses were carried out using an Excel spreadsheet (Microsoft), according to models described by Jekel et al. (1999).

\section{RESULTS}

The comparative results of the direct method (ISO 10272-2) and the enrichment method (ISO 102721) as confirmed by real-time PCR of the 80 chicken carcass samples analyzedare shown in Table 1.Twenty samples were positive only by the direct method, five were positive only by the enrichment method, and eight samples were positive by both methods. The sensitivity of the direct and enrichment methods was $84.8 \%$ and $39.4 \%$, respectively. The specificity was $100 \%$ for both methods.

Table 1 - Comparative analysis of the direct and enrichment methods for the detection of Campylobacter spp. in 80 chicken meat samples as confirmed by real-time PCR.

\begin{tabular}{lll}
\hline $\begin{array}{l}\text { Number of positive samples } \\
\text { obtained exclusively by one } \\
\text { method }\end{array}$ & \multicolumn{1}{c}{ Direct Method } & Enrichment Method \\
$\begin{array}{l}\text { Number of positive samples } \\
\text { obtained by both methods }\end{array}$ & 5 \\
$\begin{array}{l}\text { Sensitivity }(\%)^{1} \\
\text { Specificity }(\%)^{2}\end{array}$ & 84.8 & 39.4 \\
Prevalence $(\%)^{3}$ & 100 \\
\hline${ }^{1}$ Sensitivity $=($ true positive results / true positive results + false negative results) $\times 100$ \\
${ }^{2}$ Specificity $=($ true negative results / true negative results + false positive results) $\times 100$ \\
${ }^{3}$ Prevalence $=($ true positive samples $\times 100)$ / total number of samples
\end{tabular}

The overall correlation between the direct and enrichment methods was $64.5 \%$. Therefore, there was little agreement of the results between the ISO 10272-1 and ISO 10272-2 methods. The prevalence of Campylobacter spp. was $41.2 \%(n=33)$. C. jejuni, C. lari, C. upsaliensis and C. coli were identified in 33.7\% $(n=27), 3.75 \%(n=3), 2.5 \%(n=2)$, and $1.2 \%(n=1)$ of the samples, respectively, .

The results obtained from the 18 chicken meat samples, which enrichment was carried out using different rinse volumes, are shown in Table 2. Six (33.3\%) samples were tested positive by the direct method. The numbers of positive samples with rinse volumes of $2.5,5$, and $10 \mathrm{~mL}$ were five $(27.8 \%)$, four $(22.2 \%)$ and one $(5.5 \%)$, respectively. Two samples were positive only by the direct method and one sample was positive by the enrichment method with $2.5 \mathrm{~mL}$ of rinse. The sensitivity of the direct method was $85.7 \%$, and that of the enrichment method with rinse volumes of $2.5,5$ and $10 \mathrm{~mL}$ was $71.4 \%, 57.1 \%$, and $14.3 \%$, respectively. The specificities of the direct method and the enrichment method with different rinse volumes were $100 \%$.

Table 2 - Comparative analyses of the direct and enrichment methods using different rinse volumes $(2.5,5$, and $10 \mathrm{~mL})$ for the detection of Campylobacter spp. in 18 chicken meat samples as confirmed by real-time PCR.

\begin{tabular}{lllll}
\hline & $\begin{array}{l}\text { Direct } \\
\text { Method }\end{array}$ & \multicolumn{3}{l}{$\begin{array}{l}\text { Enrichment Method } \\
\text { Rinse volumes }\end{array}$} \\
\cline { 2 - 5 } & & $2.5 \mathrm{~mL}$ & $5 \mathrm{~mL}$ & $10 \mathrm{~mL}$ \\
\cline { 2 - 5 } $\begin{array}{l}\text { Number of positive } \\
\text { samples }\end{array}$ & $6(33.3 \%)$ & $5(27.8 \%)$ & $4(22.2 \%)$ & $1(5.5 \%)$ \\
$\begin{array}{l}\text { Number of positive } \\
\text { samples obtained } \\
\text { exclusively by one } \\
\text { method }\end{array}$ & 2 & 1 & 0 & 0 \\
$\begin{array}{l}\text { Sensitivity }(\%)^{1} \\
\text { Specificity }(\%)^{2}\end{array}$ & 85.7 & 71.4 & 57.1 & 14.3 \\
Prevalence $(\%)^{3}$ & $38.9(n=7)$ & 100 & 100 & 100 \\
\hline
\end{tabular}

1 Sensitivity = (true positive results / true positive results + false negative results) $\times 100$ ${ }^{2}$ Specificity $=$ (true negative results $/$ true negative results + false positive results) $\times 100$ ${ }^{3}$ Prevalence $=($ true positive samples $\times 100) /$ total number of samples

The results of the seven samples tested positive to Campylobacter out of the18 samples analyzed with different volumes of rinse $(2.5,5$ and $10 \mathrm{~mL})$ are shown in Table 3. Campylobacter was isolated by the direct method in six out of seven positive samples. The best recovery of Campylobacter after enrichment was observed with $2.5 \mathrm{~mL}$ of rinse. The correlation percentage between the direct method and the enrichment method with $2.5 \mathrm{~mL}$ of rinse was 83.3\%. In sample 13 (brand E), Campylobacter spp. was isolated only after enrichment, possibly due to 
the small number of viable cells present in the sample. In the brand D samples, Campylobacter spp. was not isolated after enrichment regardless of the rinse volume used possibly due to the high microbial contamination of the chicken carcass samples.

Table 3 - Results of the seven samples that tested positive to Campylobacter from 18 samples analyzed using different rinse volumes $(2.5,5$ and $10 \mathrm{~mL})$.

\begin{tabular}{lccccc}
\hline & & & \multicolumn{4}{c}{$\begin{array}{c}\text { Enrichment Method } \\
\text { Rinse volumes }\end{array}$} \\
\cline { 4 - 6 } Samples & Brands & Direct Method & $2.5 \mathrm{~mL}$ & $5 \mathrm{~mL}$ & $10 \mathrm{~mL}$ \\
\hline 7 & $\mathrm{C}$ & + & + & - & - \\
9 & $\mathrm{C}$ & + & + & + & - \\
10 & $\mathrm{D}$ & + & - & - & - \\
12 & $\mathrm{D}$ & + & - & - & - \\
13 & $\mathrm{E}$ & - & + & + & - \\
14 & $\mathrm{E}$ & + & + & + & + \\
15 & $\mathrm{E}$ & + & + & + & - \\
\hline
\end{tabular}

\section{DISCUSSION}

Compared with the enrichment method, the direct method yielded a higher number of positive results for Campylobacter spp. and presented higher sensitivity percentage. Similar results were obtained by Kiess et al. (2010), who obtained higher isolation of Campylobacter spp. in broiler chicken litter using the direct method. On the other hand, Kuana et al. (2008) found no statistically significant difference ( $p>$ 0.05 ) between the direct and enrichment methods in cloacae swabs and poultry carcasses.

The results obtained in the present study with the direct method suggest that refrigeration does not affect the recovery of Campylobacter spp. Maziero \& Oliveira (2010) found no significant difference in the prevalence of $C$. jejuni in chicken meat whether fresh, chilled or frozen, indicating that this bacterium is able to survive low temperature storage conditions.

Although the direct method was more efficient than the enrichment method, it was difficult to count colonies on the MCCDA and MBA plates. Hunt et al. (2001) reported that selective media with high water content, such as those used for the isolation of Campylobacter spp., can result in colonies that tend to coalesce, making them very difficult to count. Problems with colony counting by the direct method were also observed by Habib et al. (2008), after the incubation of 0.3 and $0.4 \mathrm{~mL}$ of chicken meat rinse, and the difficulty in counting Campylobacter spp. colonies was related to the sample contamination with aerobic mesophilic bacteria (105 CFU/g) and Escherichia coli $\left(10^{3} \mathrm{CFU} / \mathrm{g}\right)$.
In the same study, the difficulty in colony counting was observed even when $0.1 \mathrm{~mL}$ of chicken meat rinse was used.

Despite the efficiency of the direct method, the exclusive use of this method might compromise the accuracy of the results. The enrichment method detected five samples that were contaminated with Campylobacter spp. However, the direct method did not detect the presence of Campylobacter spp. in those samples, possibly because contamination was low and it required enrichment (Table 3). Gharst et al. (2006), Nauta et al. (2009), and Habib et al. (2011) obtained higher detection of Campylobacter spp. by the enrichment method and concluded that the number of Campylobacter spp. colonies in certain samples was not sufficient for the detection by the direct method and that the enrichment of the samples contributed to an increase in the percentage of isolation.

Jacobs-Reitsma et al . (2007), who reviewed the ISO 10272 protocol, found that the enrichment method was unsuitable for the isolation of Campylobacter spp. from refrigerated chicken meat, and suggested that a culture medium other than mCCDA should be used. In the present study, Campylobacter was not isolated in samples tested positive by the direct method after enrichment, regardless of the rinse volume used (Table 3). This have happened possibly due to the inefficacy of the antibiotics present in the enrichment broth (Jacobs-Reitsma et al., 2007) and the inability of Campylobacter spp. to outcompete the present microbial contamination (Lee \& Newell 2006).

Kiess et al. (2010) found no increase in the percentage of Campylobacter spp. after enrichment in Campylobacter Enrichment Broth (CEB) and suggested that a better recovery could have been obtained if the Preston broth, previously used by Bolton and Robertson (1982), had been used. However, an even better recovery could have been obtained by modifying the proportion between rinse and enrichment broth, e.g., 1:10had been already used by Kuana et al. (2008) and Nauta et al. (2009), instead of 1:4, used by Kiess et al. (2010).

The highest number of positive samples obtained in the present study with the enrichment method using $2.5 \mathrm{~mL}$ of rinse suggests that the rinse volume described in the ISO 10272-2 protocol should be modified. In spite of the similar number of positive samples obtained with the direct and the enrichment method using the $2.5 \mathrm{~mL}$ rinse, the use of only one method is not recommended because the correlation percentage of $83.3 \%$ is not ideal. 
It is acknowledged that only a limited number of samples (18 samples) was analyzed in the present study to test the different volumes of rinse for the selective enrichment. The results, however, showed that the volume of $10 \mathrm{~mL}$ rinse used in ISO 10272-1 (method Enrichment) could limit the detection of Campylobacter spp. and that the use of a smaller volumes of rinse (2.5 $\mathrm{mL}$ ) could provide a better recovery of Campylobacter after selective enrichment.

\section{CONCLUSION}

The direct method (ISO 10272-2) was more efficient than the enrichment method (ISO 10272-1) for the detection of Campylobacter spp. The use of the 10$\mathrm{mL}$ rinse in the enrichment method, as proposed in the ISO 10272-1 protocol, was less efficient for the recovery of Campylobacter spp. than the use of the $2.5-\mathrm{mL}$ rinse. The use of a smaller volume of rinse may be a better option due to the inefficacy of antibiotics to inhibit microbial contaminants, as well as the low competitiveness of Campylobacter spp., especially when present in low counts. The correlation percentage of $83.3 \%$ between the direct method and the enrichment method with $2.5 \mathrm{~mL}$ of rinse indicated that the exclusive use of the direct method may compromise the accuracy of the results.

\section{ACKNOWLEDGEMENTS}

This study was partially carried out at Federal University of Paraná, and it was funded by the Central Laboratory of Parana State, the Catholic University of Parana, and the Londrina State University. We are grateful to Brazil Foods S.A., Videira Unit, Santa Catarina, for the expert technical assistance in realtime PCR, and to Simbios Technology for providing reagents for real-time $P C R$.

\section{REFERENCES}

Aquino MHC, Pacheco AP, Ferreira MC, Tibana A. Frequency of isolation and identification of thermophilic Campylobacters from animals in Brazil. Veterinary Journal 2002;164:159-161

Bolton FJ, Robertson B. A selective medium for isolating Campylobacter jejuni/coli. Journal Clinical Pathology 1982;35:462-67.

Casaril KBPB. Standardization of traditional PCR and Real Time for the detection of Campylobacter jejuni and Campylobacter coli in foods [thesis]. Londrina: Department of Food Science and Technology, Center for Agricultural Sciences, State University of Londrina; 2010.

Dias TC, Queiroz DMM, Mendes EN, Peres JN. Chicken carcasses as a source of Campylobacter jejuni in Belo Horizonte, Brazil. Revista do Instituto de Medicina Tropical 1990;32:414-418.
Edson DC, Empson S, Massey LD. Pathogen detection in food microbiology laboratories: an analysis of qualitative proficiency test data, 1999 and 2007.Journal of Food Safety 2009; 29:521-30.

Franchin PR, Aidoo KE, Batista, CRV. Sources of poultry meat contamination with thermophilic Campylobacter before slaughter. Brazilian Journal of Microbiology 2005;36:157- 162.

FranchinPR, Ogliari, PJ, Batista, CR. Frequency of thermophlic Campylobacter in broiler chickens during industrial processing in Southern Brazil slaughterhouse. British Poultry Science 2007;48:127-132.

Gharst G, Hanson D, Kathariou, S. Effect of direct culture versus selective enrichment on the isolation of thermophilic Campylobacter from feces of mature cattle at harvest. Journal of Food Protection 2006;69:10241027

Habib I, Sampers I, Uyttendaele M, Berkvens D, Zutter, LD. Performance characteristics and estimation of measurement uncertainty of three plating procedures for Campylobacter enumeration in chicken meat. Food Microbiology 2008;25:65-74

Habib I, Uyttendaele M, Zutter LD.Evaluation of ISO 10272:2006 standard versus alternative enrichment and plating combinations for enumeration e detection of Campylobacter in chicken meat. Food Microbiology 2011;28:1117-1123.

Hanrahan EJ, Madupu, DG. Appleton and Lange's review of epidemiology and biostatistics for the USMLE. Englewood Cliffs: Prentice Hall; 1994.

Humphrey T, O'Brien S, Madsen M. Campylobacter as a zoonotic pathogens: a food production perspective. International Journal Food Microbiology 2007;117:237-257

Hunt JM, Abeyta C, Trant T. Campylobacterln: bacteriological manual online. 8th ed. Whashington: Center for Food Safety and Applied Nutrition; 2001.

IBGE - Brazilian Institute of Geography and Statistics. Indicadores de produção pecuária [cited 2010 Nov 30]. Available from: http://www. ibge.gov.br.

ISO - International Organization for Standardization. ISO 10272 microbiology of food and animal feeding stuff - horizontal method for detection and enumeration of Campylobacter spp. - Part 1: enrichment method; part 2: enumeration method. Geneva; 2006.

Jacobs-Reitsma WF, Overbeek WV, Dijk SOV, Aarts HJ. Implementation of ISO 10272:2006 for detection and enumeration of Campylobacter in foods. Zoonoses Public Health 2007;54 (Suppl. 1):49.

Jacobs-Reitsma WF, Lyhs U, Wagenaar J. Campylobacter. In. Nachamkin CMM, Szymanski MJ, Blaser. Campylobacter in the food supply. 3rd ed. Washington: ASM Press; 2008. p.627-644.

Jekel JF, Elmore JG, Katz DL. Epidemiology and biostatistics and preventive medicine. Porto Alegre: Artmed; 1999

Kiess AS, Parker HM, McDaniel CD. Evaluation of different selective media and culture techniques for the quantification of Campylobacter spp. from broiler litter. Poultry Science 2010;89:1755-1762.

Kuana SL, Santos LR, Rodrigues LB, Borsoi A, Moraes HL, Salle CT, Nascimento VP. Occurrence and characterization of Campylobacter in the Brazilian production and processing of broilers. Avian Diseases 2008;9:480-486.

Lee MD, Newell DG. Campylobacterin poultry: Filling an ecological niche Avian Diseases 2006;50:1-9.

Maziero MT, Oliveira TCRM. Effect of refrigeration and frozen storage on the Campylobacter jejuni recovery from naturally contaminated broilerskins. Brazilian Journal of Microbiology 2010;41:501-505. 
Nauta MJ, van der Wal FJ, Putirulan FF, Post J, van de Kassteele J, Bolder NM. Evaluation of the "testing and scheduling" strategy for control of Campylobacter in broiler meat in the Netherlands. International Journal of Food Microbiology 2009;134:216-222.

Oliveira TCRM, Barbut S, Griffiths MW. A robotic DNA purification protocol and real-time PCR for the detection of Campylobacter jejuni in foods. Journal Food of Protection 2005;68:2131-2135.
Scarcelli E, Piatti RM, Harakava R, Miyashiro, S, Campos Fernandes FM Campos FR, Francisco W, Genovez ME, Richtzenhain LJ. Molecular subtyping of Campylobacter jejuni subsp. jejuni strains isolated from different animal species in the state of São Paulo, Brazil. Brazilian Journal of Microbiology 2005;36:378-382.

Snelling WJ, Matsudac M, Moorec JE, Dooley JSG. Under the microscope: Campylobacter jejuni. Letters Applied Microbiology 2005;41:297-302. 